\title{
Analysis of the quality of electricity parameters in a wind power station
}

\author{
Sandra Mroczkowska ${ }^{1}$, Artur Nawrowski ${ }^{1}$, Ryszard Nawrowski ${ }^{1}$, Maria Zielińska ${ }^{1 *}$ \\ ${ }^{1}$ Institute of Elecrtical Engineering, Poznan University of Technology, 60-965 Poznan, ul. Piotrowo 3a, Poland
}

\begin{abstract}
The article deals in detail with all indicators of electricity quality related to the operation of wind power stations and interoperation with the power system, such as: static and dynamic voltage variations, voltage fluctuations, harmonics and quality standards of system operators. It includes the presentation of examples of measurement results as well as conclusions formulated as a result of the conducted studies.
\end{abstract}

\section{Introduction}

In recent years, electricity consumption in the European Union, including Poland, has grown dynamically. In Poland, in the year 2018, it reached the level of 170TWh, and in the European Union, about 3700 TWh per year. The thermal energy sector supplied about $65 \%$ of the produced electricity. The rapid accumulation of negative phenomena such as pollution of the environment and greenhouse effect make the search for new ecological and renewable sources of electricity necessary. One of these sources is the wind energy sector. Unfortunately this is an unstable source, which generates many operational problems and has a significant effect on the quality of electricity in the power sector.

\section{Electricity quality indicators 2.1 Static voltage}

The parallel operation of the wind farm with the power system is characterised by uninterrupted variability of this state of the system, related to the change in the generated active power. The change in the generated active power translates into the change in the value of voltage at the point of connection. The problem of static voltage variations was unambiguously defined by the applicable standard [1], where states that every week $95 \%$ of the set of 10 -minute average root mean square values of the supply voltage in the $15 \mathrm{kV}$ network should be within the range of deviations of $\pm 10 \%$ of rated voltage, excluding power failures.

\subsection{Dynamic voltage}

The inclusion of the wind turbine in the power network may cause fast transients in supply voltage variations. The value of dynamic voltage variations depends on the type of a wind turbine and the short-circuit power level at the point of connection. The problem of dynamic changes in the voltage value is subject to regulations of the international standard" IEC 61000-3-7 [1], under which the maximum voltage variation depends on the frequency of connection of the device which generates interference to the network. If the frequency of connection of the wind power station with the network is lower than 10 times per hour, the voltage variation for the $15 \mathrm{kV}$ network must not exceed $3 \%$ at the point of connection.

\subsection{Voltage fluctuations - flickers}

Voltage fluctuations are defined as fast (e.g. 0.02 $\mathrm{U}_{\mathrm{n}}$ ) variations in root mean square value of the voltage or series of such variations which do not exceed tolerance limits. These variations are usually within the tolerance limit of $\pm 5 \% \mathrm{U}_{\mathrm{n}}$. The voltage variations which go outside the range of $\pm 10 \%$ are classified as voltage dips or swells. The basic, commonly accepted criterion for the harmfulness of voltage fluctuations is the luminous flux flicker of light sources.

The flicker indicators are figures which determine the short-term flicker severity $\mathrm{P}_{\text {st }}$ and long-term flicker severity $\mathrm{P}_{\mathrm{lt}}$. The regulation of the European Union specifies the permissible values of the long-term flicker severity which are as follows:

- 0.8 for the connection points within the network with the rated voltage of $110 \mathrm{kV}$ and higher,

- 1 for the connection points within the network with the rated voltage lower than $110 \mathrm{kV}$.

\subsection{Harmonics}

Current and voltage harmonic distortions are caused by soft-start systems and electronic power converters, with which wind power stations are provided. It allows for the presentation of the distorted waveform in the form of a sum of sine waves with consecutive basic frequency multiples, i.e. harmonics. The parameter of total harmonic distortion is described in the following form :

$$
\operatorname{THD}_{\mathrm{u}}=\sqrt{\sum_{\mathrm{n}=2}^{40}\left(\frac{\mathrm{U}_{(\mathrm{n})}}{\mathrm{U}_{(1)}}\right)^{2}} 100 \%
$$

where: $U_{(1)}$ and $U_{(n)}$ - are amplitudes of the first and subsequent harmonics. 
The content of the respective harmonics is described by the respective $\mathrm{n}$-th harmonic factor. By analogy, the factors are applied to describe the current distortion. The regulation of the European Union determines the requirements for the voltage curve distortion. The total harmonic distortion (THD) must not exceed accordingly:

- $3 \%$ for the connection points within the network with the rated voltage of $110 \mathrm{kV}$ and higher,

- $8 \%$ for the connection points within the network with the rated voltage lower than $110 \mathrm{kV}$.

The content of the respective voltage harmonics referred to the basic harmonic must not exceed the values given in standards for $95 \%$ of time during each week. Also, the permissible levels of total harmonic distortion and contents of the respective harmonics are specified in the respective European Standards.

\subsection{Quality standards determined by operators}

The wind power station should not cause sudden voltage variations and surges that would exceed the level of 3\%. If voltage interferences caused by the operation of the wind power station are of repetitive nature, the range of a one-off rapid change in the root mean square value of the voltage must not exceed $2.5 \%$ for a frequency up to 10 interferences/hour and $1.5 \%$ for a frequency up to 100 interferences/hour. The above-mentioned requirements also refer to the start-up and shut-down cases for the respective units.

The short-term flicker severity (Pst) and the long-term flicker severity (Plt) for wind farms connected to the 110 $\mathrm{V}$ network and MV network should not accordingly exceed the following values:

a) $\mathrm{P}$ st $<0.35$ for the $110 \mathrm{kV}$ network and P st $<0.45$ for the MV network,

b) P lt $<0.25$ for the $110 \mathrm{kV}$ network and P lt $<0.35$ for the MV network.

In order to determine the maximum levels of emission of harmonics, receivers are divided into four classes - A, B, C and D. Permissible exemplary levels of emission of current harmonics caused by the receivers with the phase rated current $<16 \mathrm{~A}$ and $>16 \mathrm{~A}$, qualified into the respective classes, are specified in IEC-PNE standards [1].

\section{Applied measuring instruments}

The measurements were performed by means of an instrument manufactured by A-Eberle: the multi-task power quality analyser - PQBOX 200 No. 1306-107. This instrument is provided with the calibration certificate and Declaration of Compliance (all (voltage and current) measuring probes are provided with their own calibration certificates).

\section{Measurement results}

The following figures present exemplary results of registration of flicker and harmonics (ENERCON E66 turbine with a total power of $2000 \mathrm{KW}$ ) [2].

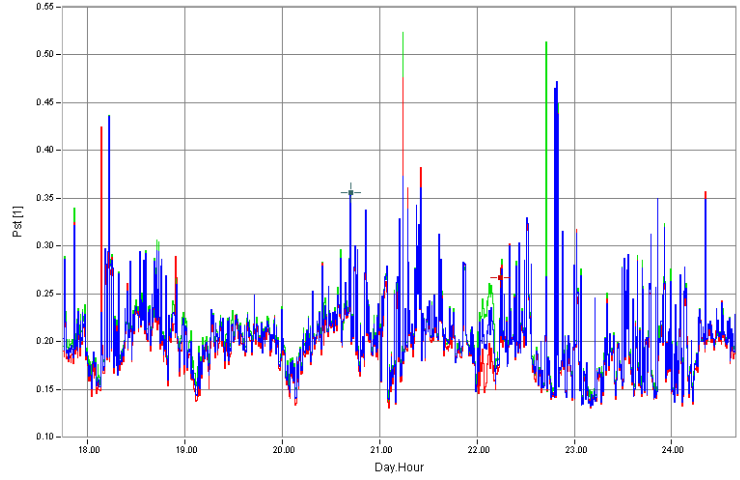

Fig. 1. Short-term flicker waveform $P_{S t}$.

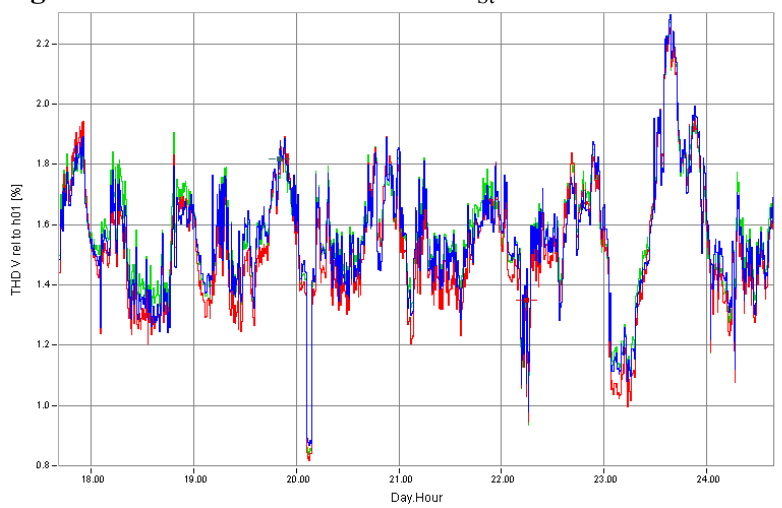

Fig. 2. Harmonic waveform - content of $\mathrm{THD}_{\mathrm{u}}$.

\section{Conclusions}

The quality of electricity generated by the wind power station with a power of $2000 \mathrm{~kW}$ and measured between 21 November 2018 and 28 November 2018, is evidence to the following facts:

1. The measurements of the recorded results allow the conclusion to be drawn that voltage is $100 \%$ within the range of permissible tolerance limits.

2. The recorded values of $\mathrm{P}_{\mathrm{lt}}$ do not exceed the value specified in the EU standard for $95 \%$ of time during the week and are as follows: 0.15 for U12, 0.14 for $\mathrm{U} 23$ and 0.14 for U31.

3. The recorded values of the respective harmonics indicate that they meet the requirements of the standard in $100 \%$.

4. No short-lasting voltage swells were detected.

5. It must be emphasised that the recorded results represented the period of only 8 selected days. In other periods, the requirements of the standards may be exceeded.

6. Therefore, for reasons related to the security of the power system, the constant monitoring of the quality of electricity is required.

\section{References}

1. Standard IEC-PN-EN 61400-21, July 2004, Wind turbines.

2. Technical and operational instructions for the ENERCON E66 wind farm. 